\title{
Analyzing the Wide Pankurdism from the Copenhagen School and Constructivism Perspective
}

\author{
Khalil Sardarnia ${ }^{1} \&$ Marzie Abedi ${ }^{2}$ \\ ${ }^{1}$ Political Sciences Department, Faculty of Law \& Political Sciences, Shiraz University, Shiraz, Iran \\ ${ }^{2}$ Shiraz University, Shiraz, Iran \\ Correspondence: Khalil Sardarnia, Political Sciences Department, Faculty of Law \& Political Sciences, Shiraz \\ University, Shiraz, Iran. E-mail: Kh_sardarnia@yahoo.com
}

Received: June 29, 2016 Accepted: July 18, 2016 Online Published: October 30, 2016

doi:10.5539/jpl.v9n9p31 URL: http://dx.doi.org/10.5539/jpl.v9n9p31

\begin{abstract}
In the (post-Cold War era), one can see violence, ethnic and religious changes in the Middle East more than any other regions in the world. In the recent years, changes and rises have made this region the central place for ethnic and religious crisis around the world. The present study aims to answer this basic question framed through two theoretical approaches of constructivism and Copenhagen school. That is, what are the most influential reasons for spreading pankurdism in the Kurdish-resident regions in the Middle East? In order to answer this question, the research hypothesis is based on some influential elements including self-governance experience in Iraqi Kurdistan as the heart and the locus for forming the dream of great Kurdistan, appearance and activation of new generation of leaders, Kurdish party and civil actors. It also includes intensification of awareness and ethnic identity-orientation among young Kurdish people, the fragility of the government in Iraq, collapse of authority in Syria and appearance and proceeding of Islamic state of Iraq and Syria (ISIS) forces. In this paper, the research method is analytical-causal explanation. The most important findings of the study is that the combination of reasons cause to make spread of pankurdism in the Kurdish-resident region and their convergence effective. These reasons are the identification among the Kurds as the result of dissatisfactions, humiliation, and suppression during several decades, the successful experience of autonomy in the Kurdish-resident regions, and collapse and fragility of authority in Syria and Iraq. In the near future, such increasing opportunities and convergences of the historical and main identity can prepare the Kurds to put pressure on the governments for autonomy or even their independency.
\end{abstract}

Keywords: Pankurdism, Copenhagen school, construction theory, Kurdish-resident regions

\section{Introduction}

During the (post-Cold War era) from 1990 until now, it can be seen the world increasingly develops in identity, ethnic-lingual and religious crises, and violence. Being more political in terms of ethnic and religious identities and other identities makes the field of studies in political sociology and international relations not to be restricted in the classical issues and discussions like governments and conflicts among governments and ranks, and to large extent move towards the identity and cultural politics. On this base, it is noted that comparing with the past, the analysts absorb more to the conflicts in terms of identity, ethnicity, language, religion and gender and the like in the field of social and political science.

In comparison to the other regions around the world, it can be said that Middle East is the most important region facing with political identity moves and ethnic and religious violence in the contemporary age. This violence is rooted in crises like politically legal crises, government-making crises, and identity crises. On this base, the Middle East is the main center for the political and social study and analysis. From 1990 decade, especially from the Arabic Spring until now, it can be observed that an ascending trace towards ethnic and religious violence and ethnic nationalism.

Among all, Iraq is the clearest place and example for the ethnic and religious violence and nationalism. The Kurdish is considered as the largest ethnic minority that does not have a government in the world. The Kurdish is dreaming over 100 years of having autonomous government and independency. Violation to Iraq, establishment of the local government in Iraqi Kurdistan, changes and the internal war in Syria and the susceptibility of 
government in Syria cause the region face with wide pankurdism. One of its consequences is to form the idea and dream of the "great Kurdistan" in the minds of the major Kurdish people in Iraq, Syria, and Turkey.

The main purpose of this paper is to provide the influential opportunities or reasons on the spread of pankurdism in the North of Middle East including Iraq, Turkey and Syria and the formation of a dream called "great Kurdistan" in the people's mind. In line with this aim, the main question is what are the most importantly influential reasons for the wide pankurdism in the Kurdish region in the Middle Est (Iraq, Syria, and Turkey)? In order to answer this question, the research theory is designed as the most importantly effective factor in making the Kurdish identity and wide pankurdism more political including the experience of an autonomy in Kurdistan, the idea and dream of "great Kurdistan" as well as the appearance and activation of the new generation of Kurdish party and civil leaders. It also includes strengthening the ethnic awareness and identity among major Kurdish young people in the region under the influence of leaders and internet cyber and satellite conditions, the internal war in Syria and Iraq and fragility of government especially after the appearance and spread of ISIS and the like.

In terms of historical background, it should be noticed that many studies in English and Persian in relation to the Kurdish is useful in this study but explaining them is beyond the scope of this study. In order to make the long story short, some of the most important studies done in English similar to the subject of the present study is mentioned. Perhaps, it can be said that the English article written by Rafaat (2007) named, as "the Kurdish independent government is either reachable or dreamy" is the most important effect that is relatively similar to the subject of the present study. However, the theoretical approach of this paper is different and not all reasons are mentioned here. Additionally, the subject of the paper is to find the root of wide pankurdism and not the formation of an independent government. Omar Tekdemir, in his Ph.D. thesis named "The paths of Kurdish political economy and political identity", studied the role of the Kurdish young and educated in the Kurdish new political identity formation from a constructive perspective. Natali (2012) in her article named "Kurdish quasi-government" investigated the hurdles in establishing the government whose approach and subject is far more different from what is investigated in this paper. Ala Jaber Muhammed (2015), in his Ph.D. thesis under the title of "The Politics of Iraqi Kurdistan; Toward Federalism or Secession?" investigated the Kurdish students' views in Iraq in relation to the future of Iraqi Kurdistan in terms of federalism or independency.

On the a whole, regarding reasons such as the lack of direct influence of this issue or the difference in theoretical approaches of this research comparing with other researches done in this respect, such a research seems to be of great importance and innovation.

\section{Methodology of Research}

This paper benefits from an analytical-causal explanation method. The theoretical approach used in the research is as follows: the historical and political sociology, the theory of "Copenhagen social immunity" and "constructivism". The method for gathering data is library- and internet-based one.

\section{The Conceptual and Theoretical Principles of the Research}

In this paper, the two relevant theoretical approaches, that is, constructivism and the theory of "social security" stated in the Copenhagen school are used to elucidate and explain the roots and reasons for the wide pankurdism in the Kurdish-resident area.

The term "social security" means security and insecurity threats do not happen in vacuum but they are the result of the society and variously cognitive, intellectual, social, and political conditions. From this perspective, Buzan knows security and insecurity threats as an inter-subjective and social issue that is known, formed, and changed in the society (Abdullah Khani, 2006, 494). From this viewpoint, an issue with great importance in terms of security for a society may not be that much important in another society. The social security is related to pivotal threats; that is, it threatens the social and collective security and identity.

Based on the kind of social security mentioned by Copenhagen school, identity is the key and central concept (Buzan et al., 2007). Once a group feels its descendant's cultural beliefs and approaches are rejected, controlled, or changed, the group feels disappointed (Nasiri, 2011, 110). Based on Copenhagen school, security has individual and identity aspects and comparing to other threats response to these kinds of threats, are more violent and radical. With an implicit emphasis on norms, identity and social immunity, Copenhagen school has some kind of constructive ontology. Therefore, this school is closely related to the constructivism approach. In fact, this theory is a combination of material and constructivism strategies. Once the ideas related to the territorial status of a country and power distribution are noticed, it is close to the neo-realistic strategies and once 
securitization process is viewed as the result of actors' inter-subjective interaction, then the constructivism strategy is bolder (Sedive, 2004, 461).

"Securitization" is one of the most important concepts in Copenhagen school. Weaver noted that security is understood better as the discursive act than verbal action. Buzan and Do wild also emphasized that security was an act that moved policy beyond the fixed rules of games (Abdullah Khani, 2003, 148). Buzan and Weaver knew securitization as an act linked to the person, group, or government; that is, security and identity of a special social group, its values, and interests are closely related through a social and ontological approach (Abdullah Khani, 2003, 149).

For Buzan, it was not possible to separate the social threats from the political ones. From this complementary viewpoint, the social threats occur when social security of a government is in danger. Buzan argued that the social security was the ability to maintain and immunize the traditional patterns of language, culture, and religious or racial identity and then, the new political-social revolution or change was considered as a threat to the social survival and identity (Buzan, 1999, 36). Concerning Buzan's definition of the social insecurity, the social identity has political connotations. On this base, a minority response to defend their own identity naturally is considered as a political act. There are many ethnic and religious groups and communities that do not have any government. Therefore, threat to their identities is both social and political. In most cases, the political boundaries are not in accordance with the social distinctions and ranking. Thus, that ethnic group, consider any kind of social, economic, and cultural distinction as a social and political issue that has political consequences (Nasiri, 2011, 109)

The constructivism approach or theory is a deeply-rooted attempt in the field of metatheory. In terms of metatheory, the followers of this theory intermediate between naturalist and positivist on the one hand. In terms of content, they intermediate between realism and liberalism, on the other hand (Moshirzadeh, 2010, 315).

The constructivism is shaped on this attitude that realities such as security, security threats, and collective acts such as ethnic and regional nationalism are constructed and cannot be studied independence of activist and their identity, cognition, norms and values. Reality is an inter-subjective item that is made through time and society. In such social content, the activists, ethnic, religious, lingual and gender based identities, make interaction, communication and understand each other collectively and finally a collective act occurs among them which nationalism and collectively ethnic and religious act is one of these issues. Hence, unlike positivists, they do not consider reality as a fixed, constant and previously determined and defined entity. Human beings build their own history and identity within the world framework and in this way, they achieve awareness (Lesser \&et al., 2000, 24-48).

From constructivists' perspective, reality is happening and it is not a fixed entity. Hence, identities would change and consequently behaviors, acts, and implications change as well. From the epistemological perspective, the constructivists do not believe in reality as an objective, innate and previously determined, since they rejects independency of the objectivity from subjectivity. Therefore, in terms of epistemological perspective, constructivism intermediates between positivist and meta-positivist. In the logic of genetic constructivism, human being is considered as an entity formed in the society; society in total is an entity formed in the history as well. From this perspective, those persons who are made by their own history can make their own history fruitfully as well.

One of the most important issues in constructivism in the ontological level is the mutual relation between agent-structure. From constructivists' perspective, structure and agent complete each other mutually. Structures are considered as relatively stable phenomena with mutual interaction that are created. Based on these structures, the activist defines their identity and interests (Wendt, 2005, 114). From the constructivists' perspective, the structure does not exist out of activists' approaches.

In a whole, it should be noted that like theorists of Copenhagen school, for constructivist, the social issues like security and security threats takes identity and social aspects. Each implication of security and insecurity threats is the result of the relation between inter-subjective and interaction of activists in the form of intra-identity but it occurs in the present internally, regionally and even internationally social conditions, temporal and spacial boundaries. From this perspective, nationalism and ethnic solidarity roots in threats and the collectively bitter experiences, as well as identity signs, myths and values with the aim to release from hegemony of "others".

\section{Geography of Kurdistan at a Glance}

Kurdistan is the mountainous place in the Middle East. From the ecological perspective, it is the habitat and home of the Kurds. This region includes parts of west and northwest of Iran, east and south-east of Turkey, north, 
and north-east of Iraq and Syria and west of Caucasus as well. On the other hand, Kurdistan is located among five governments in the Middle East; that is, Iran, Turkey, Syria, Iraq and Armenia and four civilized and cultural constructions, four plateaus, e.g. Iran, Saudi Arabia, Anatolia, and Caucasus and on the pathway to three continents, e.g. Asia, Europe, and Africa (Hafeznia, 2006, 11).

The geographically closed location of Kurdistan is geopolitically the biggest eternal challenge. Therefore, any kind of exchange with the world, absorbing cooperation of other countries especially Iran and Turkey is prerequisite in this respect. After the Arabs and Fars, the Kurds are the largest racial group in the Middle East that has sustained their ethnic distinctive features for more than 2000 years. Kurdistan is surrounded by lands and has no way to the water. Therefore, geographical separation is geopolitically its biggest challenge. However, the Kurds are distributed in these countries; those areas in which they are accommodated are very close to each other. In fact, they have shared border (Milton, 2004, 235). This perse can cause the friendliness of the Kurds with each other and their compatibly collective action for independence and sheltering the relatives. Of course, in other sources, the Kurdish population is estimated at 30 million. The Kurds are considered as the largest ethnic minority with no government in the world (Mohammad, 2013, 4).

Table 1. Estimation of the Kurdish population in 2005 (Kaveyanirad, 2010)

\begin{tabular}{ccc}
\hline Country / region & Population in million & Ratio in total (\%) \\
\hline Turkey & 13 & 20 \\
Iraq & $4 / 2$ & 19 \\
Iran & $5 / 7$ & 9 \\
Syria & $1 / 1$ & 8 \\
Immigrant abroad & $/ 9$ & --- \\
Total & $25 / 1$ & --- \\
\hline
\end{tabular}

\section{The Roots and Reasons for the Spread of Pankurdism in the Kurdish-Resident Regions}

\subsection{Dissatisfactions and Experiences of Historically Shared Bitter Experiences as an Important Motive for Pankurdism}

Within the framework of theoretical and methodological approach in historical sociology, it should be mentioned that widespread phenomena and events have historical background and are not the product of one or two decades. From this perspective, the contemporary wide pankurdism rooted in shared social, cultural, economic, and political dissatisfactions. Similarly, it should be noted that more politicization of Kurdish identity and spread of pankurdism in the Kurdish-resident regions at the present time can be investigated and analyzed in accordance with the framework of identity theories for the constructivism foundation and Copenhagen school.

From the time the modern government has been established, the Kurds in the region always are faced with constant identity crisis, suppression, and humiliation by the government. Thus, always a shadow of serious deprivation is sensed in a way that passing these deprivations require to pay highly in terms of life, property, and mind. The chemical aerial bombardment of the Kurds in Halabcha is a very bitter example for the Kurds and such an event has never been forgotten. Within the framework of social immunity and constructivism approach, it should be said that Kurds experienced insecurity or faced suppression while governed by the majority of the Arab and Turks. The extent to which they faced insecurity threats is very widespread.

One of these most important threats is the denying of the Kurdish identity in Iraq, Syria, and Turkey. The Kurds always feel insecure when their social and cultural beliefs and approaches are rejected, controlled, or changed. Such an identity rejection is rooted in imposed and suppressive state-nation building that are governed by the majority of the Arabs and Turks. Such an obligatory assimilation background in these countries made a bitter experience and negative feeling and shared hatred among the Kurds. Such an experience, however bitter, underlies and supports the identity foundation for political preparedness of pankurdism and the ambitious dream to establish great Kurdistan among the Kurds (Smith, 2016, 3). One of the most important examples of the Kurdish identity denying and humiliation is the way they are referred in Turkey as "mountain Turkish". Another obvious example is to avoid the citizenship rights for 100,000 Syrian Kurdish from 1962 until now by the dynastic government of Al-Assad in Syria (Rafaat, 2007, 288). 
Arab and Turk governments mostly have used exclusive and intimidate policies and strategies in relation to the Kurds. In this respect, some important examples such as exile, expatriate, immigration, obligatory immigration, obligatory political assimilation, lingual, political and cultural chauvinism, collective slaughter, demolish of Kurdish-resident countries and cities, suppression and execution of severe security order on this ethnic group can be mentioned (Salih, 2005, 85).

Formal identity formation in Turkey, Iraq and Syria in favor of governing majority of the Arabs and Turks results in sever identity denying, humiliation and ontological insecurity among the Kurds, on the one hand and the rejection of their political and citizenship rights, on the other hand. In Turkey, the politically monolithic structure of governance closed the public sphere to any identity-based Kurdish action and their citizenship rights and prevented them from taking part in the political and media-based processes to articulate their ethnic and citizenship dissatisfaction and demands. In Turkey and Iraq, a combination of "carrot and stick policy" is applied in respect to the Kurds, the present evidence shows that their policy weighs up on stick rather than an encouraging policy. Such a policy was used in Iraq more than Turkey (Al, 2015, 7-8). In Iraq, before Saddam's overthrow, due to the reasons mentioned here, there was no feeling of serious belonging to be named under the title of Iraqi national identity and indication. Moreover, the Arab and Baath government (Mohammed, 2013, 3) surrendered the Iraqi Kurdish but due to the harshness of the government and high cost of life and property resulting from independent action, they were forced to stay silent. Saddam's overthrow gave them a serious opportunity to achieve their goals for independency.

In whole, a combination of ethnic and lingual identity based dissatisfaction of the Kurds in the region and sever and disappointed conditions for their political, social, cultural, economic life in Iraq, Turkey, Syria have been lead to form and internalize a kind of shared identification, suffering, emotion, and cognition among the Kurds for more than a century. Such historical background for identification among the Kurdish after Saddam's overthrow and brutal events in Syria and Iraq, gave the Kurds a serious opportunity to utter the dream for pankurdism and the idea of great Kurdistan. Today, those suppressed dreams for nationalism and independency act as an important motive to mobilization of Kurds and pankurdism. The ethnic and oligarchic structure of political power in the region and suppressive methods of governments has been lead to weaken and severe legitimate crises in such governments among the Kurds.

\subsection{Establishment of Kurdistan Regional Government as an Important Motivational and Political Impulse}

Iraqis Kurdistan is considered as the heart of great Kurdistan since it connects Iranian Kurdistan and Turkish Kurdistan to each other, on the one hand and has shared borders with the Kurdish resident regions in Syria, on the other hand. Iraqis Kurds as the largest non-Arabic minority, who reside in provinces Sulaymaniyah, Erbil, Dahuk, Mosul and Kirkuk, have a population about one fifth of the total population in this country (Risdel and Blake, 1990, 213). From the time the modern government is established, the issue of great Kurdistan among the Kurds and identity-demanding of this ethnic group has been always problematic for the Iraqi government in a way that in some cases it has challenged the political system and territorial integrity. Therefore, governments' attempts for the cultural unity and assimilation are not fruitful at least by the end of Baath government.

Until now, the Kurd leaders have been under the influence of variables such as Iraqi internal policies, regional conditions, the games of the neighbor countries, and internal and intergroup challenges of the opposite parties. Furthermore, issues such as great Kurdistan, self-governance, federalism are on the table more or less.

In April 1991 after the second Persian Gulf war, according to the framework of resolution 688 of the united nation security council (UNSC), Iraqis Kurds were located under the security cover of American and English fighters in the no-fly zone above circuit 36 degrees and established the first de facto government (Robin, 2003, 9). On the May 9, the first parliamentary election in Kurdistan was executed and its autonomy was recognized by the Iraqis federal government by the act of constitutional law in 2005 (Mohammed, 2013, 5). In spite of this, the majority of Arabs, especially Sunni Arabs rejected federalism; it was not executed in other areas of the country as well.

From the Kurdish self-governance in 1992 until now, this government has been executing to govern procedures and affairs in a local autonomy by sustaining commitments and connections to the central government. In fact, the Kurds in the north of Iraq have the Kurdish parliament, government and security forces and try to get more rights in this respect. The Kurds in Iraq after Saddam's overthrow are the second largest fraction in Iraqi commission after Shia coalition and have political positions such as president, one of assistants of prime minister and ministries such as the foreign minister of Iraq. However, after Saddam, though Shia groups accepted disarmament, the Kurdish local government in Iraq and the two general Kurdish parties not only sustained their own military forces but also increased the military and equipment capability so that they could strengthen their 
own support by presenting political demands and influence on the political system while it was forming. On the other hand, the Kurds gained accurate, executable, and complied design and program by using of political organization and their historical experiences.

This several years of political experience in the region of Kurdistan in Iraq determines the biggest period of internal self governance in the history of the Kurds after one-year life of Mahabad republic (1944-45) that some Kurds name it as "the golden age of the Kurds". Although now the autonomy of the Kurds is not feasible, it should be noted that such a golden age with the political authority of the Kurdish autonomy in Kurdistan has noticeable influence on the spread of wide pankurdism and enliven their suppressed dreams for independency and identity mobilization.

However achievement and execution of the idea for "great Kurdistan" now is not feasible, but the Kurds' seriously emotional and motivational support in this respect cannot be denied. The Kurds in Iraq do not agree on the issue of independency from Iraq much. However, they experienced the sweet taste of autonomy in more than one decade. In other words, the Kurds are the most serious advocates of federalism in Iraq. However, they want independency deeply; most of them are activists and believe that independency will not be possible in Iraq by the time other countries like Turkey resist against it. Therefore, federalism is the first best option for the Kurds now since federalism gives the Kurds the chance for decision making in most of the political and social issues. On the other hand, federalism enables them to defend their identity.

In this respect, the result of the qualitative and quantitative studies by Mohammed is conspicuous. The findings of his study based on the questions answered by the Kurdish university students shows that all Kurds believe that they deserve to have an autonomous government but most of respondents, approximately 80 percent in the state universities, and 91 percent in non-state universities, know such a big dream impossible due to some realistic reasons. Therefore, they know federalism is the best possibility for achieving the Kurds' goal. From the respondents' perspective, Kurdistan independency faces with obstacles like lack of international recognition, disagreements and threats by Arabic and Turkish government in the region, lack of economic independency in Kurdistan, and other reasons (Mohammed, 2013, 325-329).

In a whole, establishment of the Kurdish autonomy in the north of Iraq is considered a hopeful horizon. The reflection of such affair greatly influences the Kurds and their attempts to identity recognition in the present time. For this reason, the evolution path for the Kurds' autonomy in Iraq acts like an importantly emotional, motivational, and political support towards establishing the ideal of great Kurdistan. Barzani, the present president of Kurdistan, believes that the Kurds in four countries in the region form a shared nation and have the legitimate right to establish the Kurdish independent government (Rafaat, 2007, 275). Federalism in the north of Iraq is a form of a government that can act like the successful pattern of governance for the Kurds in the neighbor countries in the region and also is a threat for the territorial integrity in these countries in which the Kurds' citizenship rights are not recognized. Although the Iraqi Kurdistan has not been recognized as the government, it can be a central focus on being introduced regionally and internationally the Kurds as the social and political forces effective in national and international policies through the gradual development of operational independency and their own success. In specific, Iraqi Kurdistan becomes a locus to absorb the Kurdish nationalism in the region and a focus for public opinion more than before (Rafaat, 2007, 289-290).

First, the autonomous government in the north of Iraq is effective in establishing this belief and hope among the Kurds to be effective in controlling their own destiny despite of the experiences and defeats. Second, the territory of the autonomous government in the north of Iraq is seen as a communication base for Kurdistan with the organizations and internationally public opinion by which they can decrease the pressure of the government in the region. In the same line, start and development of cultural and social activities in Iraqi Kurdistan in the region as well as the development of the social communications among the Kurds in the Middles East and the north of Iraq can cause to introduce the autonomous government among the Kurds in other countries more.

In a whole, concerning the future of the Kurds in the Middle East, it can be said that the Kurds in Iraq, Turkey, and Syria will be in the situation that the regional and trans-regional actors cannot ignore their capability and capacities. Now, realities show the international necessity to recognize the Kurds as the nation that deserve autonomy. Therefore, in the near future, the countries in the region have no way but to recognize the Kurds and an independent government for the Kurds as well.

\subsection{Formation of Fragile Governments in Iraq and Syria as a Historical Opportunity}

In the theoretical literature, it is believed that the social movements and collective actions are needed to the appropriate political opportunities for effective spread and development. One of these most important opportunities is the weakness of the central government or lack of a central vigorous power. This opportunity 
acts like an impulse, catalyst, or intensifier for pankurdism. Lack of the central vigorous power in Iraq has decreased for the Kurds the highly costs of pankurdism and their protest social action.

By beginning of the second war in Persian Gulf and the imposition of international sanctions by the united nation on Iraq at the time of Saddam government in 1990s, internal atmosphere gradually led to weakening the central government in Iraq. In this respect, a new wave of pankurdism started from the beginning and the Kurds used political supports and internationally humanitarian supports. It is said further that declaration of no-fly zone by the united nation was one of the internationally appropriate conditions for the Kurdish trend.

After 2003 by Iraq occupation and Saddam's overthrow, the political levers for Kurdistan noticeably changed and the power balance become heavy on the side of the Kurds and the political entity of self-governing was established by an unrecognized formation and recognition of the Kurdish regional government. In contrast, the Iraqi government became a weak government due to war and internal violence. After 2003, widely financial sources for this region were established. Based on the constitutional law, 17 percent of the national fund was dedicated to this region. The fund for this region increased from 2/5 milliard dollars in 2005 to 13 milliard dollars in 2014 (Natali, 2015, 147).

The Kurdistan region used its oil infrastructures and development of oil fields in its territory as a lever to make political pressure on Iraq. Establishment and use of oil and gas lines from Kirkuk to Turkey was effective in strengthening financial sources and ethnically national feelings. Lack of central power and increasingly constant security crises was an opportunity to decrease or none intervene of the central government in Iraq in affairs of this region. Such an opportunity may likely help to establish a Kurdish central government in Iraq in the near future.

In a whole, the formation of self-governing government in Iraqi Kurdistan increased the Kurds' inward desire for independency. The self-governing region of Iraqi Kurdistan used the internal crises in Iraq to strengthen their own power in line with their power in other different aspects such as increasing financial income, strengthening the Kurds' ethnically patriotic emotions in the Kurdish-resident regions, increasing international support and help and developing energy and economy (Natali, 2015, 147). However, there were internally political challenges and conflicts in the parties and among the Kurdish leaders as well as international hurdles that avoided such an inward desire and historically rooted dream for independency became successful. In the meantime, it was an undeniable that lack of a central government brought the ethnically nationalistic fervent among the Kurds (Raafat, 2007, 289).

In addition, the internal war and its intensification in Syria greatly and severally influenced the spread and strength of pankurdism and regional convergence among the Kurds in Syria, Turkey, and Iraq. The Kurds were the largest racial minority in Syria and the Kurdish resident area located in north and northeast of Syria in some areas including Al-Hasakah Governorate, Al-Raqqah, and Alepp. Syrian Kurdish had only 10 percent of the population in this country and the Syrian Baath government in Syria had always rejected the entity of the two million Kurdish communities or even omitted them from the statistical population of the country (Akhavan Kazemi and Vaysi, 2014). In fact, the citizenship right had not been awarded to them for a long time and now some of the Kurds are not considered as the citizenship as well (Yildiz, 2005, 25).

Demolish of central government power in Syria made a great opportunity for the Syrian Kurds in order to organize and strengthen logistically, financially, militarily, and organizationally. Moreover, such an objective condition and opportunities had been greatly effective in the cognitive and emotional dimension of the Kurds in a way that showed clearly the ethnically national feeling of the Syrian Kurds who were more conservative in comparison with Turkish and Iraqi ones. In the objective and practical dimension, collapse of power and severe weakness of government in Syria led to form a political self-governance among the Kurds. Bashar Al-Assad's government also was silent tactically as the result of internal instability and none support of Kurds against the general parts of secular opposition and Arab-selfies as well. However, it cannot be said surely that this relative self-governing of the Syrian Kurds will continue, such a self-governing in some extent like self-governing of Iraqi Kurds can be a conspicuously political impulse and motivation for pankurdism and ethnically and politically emotional convergence in the region and prepare the world to recognize the Kurds internationally.

5.4 Appearance and Development of ISIS as an Important Opportunity for Pankurdism with an Emphasis on Kubani event

The appearance and development of ISIS has been effective from several dimensions on strengthening pankurdism and convergence of the Kurds in the region. Such aspects are:

1) Intensifying the weakness of government in Iraq and the collapse of central power in Syria. 
2) Political and legitimate susceptibility of Turkey especially after occurring several suicide attacks and bombing in the country by ISIS and increasing political motives of the Kurds in the two recent years.

3) The Kubani's influential effect and release of this city on Kurds.

4) The increased Convergence of Kurds, as the result of the brutal attacks by ISIS on the Kurdish-resident region in Iraq.

Meanwhile, the event of Kubani may be considered as the seriously starting point in strengthening pankurdism nationally and locally. Occupation and murders by ISIS in Kubani was like a very important and emotional catalyst that acted as a means to unite the Kurds militarily, humanly, emotionally and symbolically in the region. After this event, the Kurds in the region buried the hatchet and united for fighting with the armed ISIS forces. In terms of political order, after ISIS Takfiri Salafies' attack to the Kurds, the cooperative relation between the Kurds and the Kurdish parties with the free Syrian army ended.

The Kurds used the event in Kubani in 2014 and 2015 and its liberation from ISIS occupation as a nationally new Kurdish myth of the heroinism and their liberation. The ISIS crimes in Kubani caused a deeply negative influence on the body of the Syrian Kurds and the region. However, in the mean time it was very effective in strengthening the Kurdish identity as well. Moreover, it was an important emotional, motivational, political, and spiritual source for the transnational links for the Kurds in the region (Gunese and Lowe, 2015, 2). Such a resistance caused to increase the importance of the Syrian Kurds and their activity in the region that were not active and did not have much serious fighting background in comparison with the other Kurds in the region. Before the event in Kubani, the Syrian Kurds were under the influence of developments in Iraqi Kurdistan and Turkish Kurdistan. However, now they have earned more value in terms of influence and their elites are more active and influential in this respect.

\subsection{Communication and Information Revolution and the Appearance of the New Generation of the Kurdish Leaders and Young}

Undoubtedly, communication and information revolution play important role in intellectual, motivational and identity-based assimilation for the social activities. Internet and satellites are effective to develop the trend of pankurdism in several perspectives: 1. Increase the generational development and appearance of the new generation of the Kurdish young. Of course, the role of educational system and other factors in this revolution should not be ignored in this respect. 2. Intensifying the political and social awareness among the Kurds 3 . Political mobilization of Kurds by identity integration, communication and interaction, information exchange and integration of activities and objections. 4. Earning of international legitimacy and increased attention of public opinions and international associations to the Kurds and the issues of human being rights and their state of being oppressed.

Internet and satellites play important role in self-seeking and increasing political and ethnical awareness of the Kurds. In the contemporary cyber age, the physical boundaries that separate the Kurdish regions from each other is not an issue at all (Rafaat, 2007, 289). In the new cyber age, the new generations of the educated young and new leaders are very active for the Kurdish rights. Using cyber and internet connections, the Kurds are in charge of directing pankurdism and continue their way increasingly, and developmentally.

Tekdemir, in his valuable study on the Kurds, concluded that now the Kurdish identity seeking was severely distinctive in comparison with the past, this distinction involved several important elements and parts including: 1. More opportunity for young people, 2. Secularism and non-religiousness, 3. Leftism and serious aspects of socialism, 4. Serious desire for great Kurdistan, 5. Bridging among various Kurdish dialects. However, the new generation of the young and leaders has been very effective in appearing and developing identity seeking among the young. The new identity seeking among the Kurds by taking energy from the young will not be restricted to the political boundaries, restrictions, and state- nation's controls. Therefore, there is a serious tension towards the idea of great Kurdistan. The new Kurdish identity seeking is ethnicity-based without religious attachments that are greatly developed and leaded by the new generation of the university and internet young who do not has any idea to clan and religious connections unlike the previous generations (Tekdemir, 2012, 210).

\section{Conclusion and Future of Pankurdism}

In the present age, ethnicity is a phenomenon that is highly bolded in the political movements and conflicts in most developing countries and some developed ones. Middle East becomes the main locus for the ethnic conflict and nationalism around the world. In the two recent decades, the Kurdish-resident regions in Turkey, Iraq and Syria has faced to resuming of pankurdism. Meanwhile, the successful formation and experience of self-governing in Iraqi Kurdistan, weakness of government in Iraq, demolish of the central power in Syria and 
the like have been effective in the spread of pankurdism. Among the most Kurd residents in Iraq, Turkey and Syria, there are some desire for pankurdism and even independency as a rooted dream but most of the Kurds resident in these regions believe that it is not feasible in practice due to some challenges and hurdles despite of such a historically rooted dream for great Kurdistan. Therefore, they know self-governing is more realistic in terms of federalism. The most important hurdles and challenges of independency and formation of national government in great Kurdistan are:

1) Serious disagreement of all governments located in this region with the Kurdish independency.

2) Financial and economic inadequacy for economic independency.

3) Political disagreement among the leaders and the politically Kurdish mainstreams towards the independency of great Kurdistan, even the Iraqi Kurdistan knows this topic as unrealistic.

4) Lack of the serious support by Iranian Kurds for independency.

5) Internal conflicts on power in Iraq and Syria (Natalia, 2015, 153-155) and

6) Lack of serious international support. The analytic explanations of these hurdles are beyond the scope of this study but it is necessary to be mentioned in brief for determining the future for pankurdism.

In a whole, the study aims to investigate the roots for spreading pankurdism especially in the recent decade. It can be concluded that a form of shared identification, suffering, emotion and cognition among the Kurds in the region for more than one century due to the combination of ethnic-lingual based dissatisfaction among the Kurds in the region. Furthermore, the Kurds' unpleasant and difficult conditions for political, economic, cultural, and social life in Iraq, Turkey, and Syria are effective as well. With an emphasis on such a historical support for identification, the Kurds find a serious opportunity to utter the dream for pankurdism and the idea of Great Kurdistan after Saddam's overthrow and the recent brutal events in Iraq and Syria. In the contemporary age, the suppressed dreams for nationalism and independency acts like an important motive for assimilating the fundamental identity of the Kurds and pankurdism. However, due to the reasons mentioned here independency is not feasible but such an emotional, political, symbolic support and convergence in the region resulted from pankurdism make the countries in the region to accept the Kurds' self-governing in the near future. Moreover, the public opinion and international associations also accept the Kurds' rights for self-governing and probably independency.

Long-term success in the trend of independency for the Kurds as effective, political, and social forces depends on various conditions and states; it is the Kurds' ability and attempt to solve political conflicts, intensify regional interactions and convergences for the fundamental identity. It also includes the useful application of the regional and transregional power competitions, increasing financial and economic sources and capabilities, the effective use of media especially internet and satellites for ethnic convergence and international legitimacy, the use of international pressure levers like the democratic conditions mentioned in European association on accepting the Kurds' citizenship rights.

\section{References}

Abdollahkhani, A. (2006). The study and criticism of the theory of securitization. Research Center for Strategic Studies, 9(33), 491-512.

Al, S. (2015). Kurds, States Elites \& Patterns of Nationhood in Iraq \& Turkey. Project on Middle East Political Science.

Barkey, H. J. (2014). Preventing Conflict over Kurdistan. Carnegie Endowment for International Peace. Washington DC.

Buzan, B. (1999). People, States, and Fear (Translated by Research Center for Strategic Studies). Tehran: Research Center for Strategic Studies.

Buzan, B., Wæver, O., \& Wilde, J. (2007). Security: A New Framework for Analysis (Translated by Ali Reza Tayeb). Tehran: Research Center for Strategic Studies.

Drysidel, A., \& Blake, G. (1990). The political geography in the Middle East and North of Africa (Translated by Dorre Mirheidar). Tehran: political and International Studies of Foreign Ministry.

Gunese, C., \& Lowe, R. (2015 July). The Impact of the Syrian War on Kurdish Politics Across the Middle East. Chatman house Institute.

Hafeznia, M. (2006). The influence of self-governing in the Kurds in the north of Iraq on the neighbor countries. the Geographical Research Quarterly, 83, 5-36. 
Kaviyani Rad, M. (2010). Regionalism in Iran from a political geography perspective. Tehran: Strategic studies.

Lesser, E. (2000). Knowledge and Communities. Boston: Butter Worth. Heinemann.

Milton, E. (2004). Policy and government in Middle East (Translated by Rasoul Afzali). Tehran: Bashir Publication.

Mohammed, A. J. (2013). The Politics of Iraqi Kurdistan; Toward Federalism or Secession? PhD Thesis, University of Canberra. Australia.

Moshirzadeh, H. (2010). Revolution in the theories of international relations. Tehran: Samt Publication.

Nasri, Gh. (2011). Theoretical contemplation in Buzan's findings and difficulties in the Study of immunity. Research Center for Strategic Studies, 4(14), 105-134.

Natali, D. (2015). The Kurdish Quasi-State. The Washington Quarterly, 38(2), 145-164. http://dx.doi.org/10.1080/0163660X.2015.1064715

Rafaat, A. (2007). An Independent Kurdish State, Achievable or Merely a Kurdish Dream? The Journal of Social, Political \& Economic Studies, 32(3), 267-300.

Robins, P. (1993). The Overlord State: Turkish Policy and the Kurdish Issue. International Affairs, 69(4), 657-666. http://dx.doi.org/10.2307/2620591

Salih, K. (2005). What Future for Kurds?. Middle East Review of International Affairs, 9(1), 93-95.

Sedive, J. (2004). Regions and Powers: The Structure of International Security (A Book Review). Journal of International Relations and Development, 7.

Smith, B. (2016). Kurdish Separatism in Comparative Perspective. Retrieved from www.government.art.cornell.edu/.../smith

Tekdemir, O. (2012). Trajectories of Kurdish political Economy and Political Identity. PhD Thesis. Durham University.

Wendt, A. (2005). The social theory of international Relations (Translated by Homeyra Moshirzad).Tehran: Foreign ministry publication.

Yildiz, K. (2005). The Kurds in Syria: the forgotten people. London: Pluto Press.

\section{Copyrights}

Copyright for this article is retained by the author(s), with first publication rights granted to the journal.

This is an open-access article distributed under the terms and conditions of the Creative Commons Attribution license (http://creativecommons.org/licenses/by/4.0/). 